\title{
IOT ENABLED PNEUMATIC GEAR SHIFTING IN TWO-WHEELER
}

\author{
S. Divya \\ Asst. Prof., Department of Mechanical Engineering, \\ Sri Eshwar College of Engineering, \\ kondampatti[post], Vadasithur(via), Coimbatore -
} 641202.

\begin{abstract}
The present automatic transmission is fully mechanically controlled and costs very high. In this study, a gear shifting mechanism was designed and applied on a featured bike to make the gear transmission process faster and less destructible for the driver using internet. But the gear transmission mechanism designed makes driving easier and to achieve efficient driving. This new device must be reliable, has small dimensions, economical and low maintenance cost. This project aims to improve the gear shifting process with a suitable control mechanism to implement in clutch featured bikes. According to the suggested gear shifting method, which selects the transmission gear as per the speed of the vehicle without direct human interference. A pneumatic shifter is a mechanical device that uses compressed air to shift a gear controls the engaging and disengaging of gears using internet of things principle to control automatically. There is no lag time in a gear shifting operation and taking hold in the rest of the vehicles.
\end{abstract}

Keywords: Efficiency, Wear and Tear, Pneumatic

\section{INTRODUCTION}

This invention relates to control mechanisms and more particularly to mechanisms for controlling the selection and establishment of various gear relations of automotive vehicle transmission gearing. Our Invention relates to gear shift mechanisms particularly such as are used on automotive vehicles. It has for one of its principal objects to provide a gear shift mechanism pneumatically operated, through the instrumentality of which the various gears in the mechanism may be made operative. Other objects are to provide a gear shift mechanism which is noiseless in its operation, which greatly relieves all strain on the parts with which it is connected, which has no parts easily broken or apart to get out of order,

\author{
Dinesh KK, Abishek S, Bala Ganesh M, Gokulkrishnan S \\ Students, Department of Mechanical Engineering, \\ Sri Eshwar College of Engineering, \\ kondampatti[post], Vadasithur(via), Coimbatore -
} 641202.

which may be operated with but slight skill on the part of the driver, which is suitable for all makes of automotive vehicles. And which can be manufactured at a relatively low cost. As a rider when we have control over the gear shifter, typically with the rider's left foot and to operate both the clutch and brake, drivers both hands \& foot remains busy. To shift the control of gear, in hand from foot $\&$ to provide safety \& comfort to driver is the need from the perspective of Ergonomics.

\section{LITERATURE REVIEW}

1. Mankar N.A, et al describes that their project is an electro-pneumatic gear shifting mechanism in which the control unit selects optimum gear shifting ratio for an automobile automatically.

2. Vijay Jadhav, et al describe that their project is a semiconductor gear shifting mechanism in which the driver can select the gear transmission without moving his hand from the steering wheel by putting the gear shifting push buttons in the steering wheel.

3. Amol shitole, et al describes that their project is mainly designed for handicapped persons who are unable to shift the gears by their foot. They are using solenoids to shift the gear and the solenoids are mounted on both sides of the gear shifting pedal from which the person can easily shift the gear.

4. N.Venkatesh, et al describes that their project which is a pneumatic gear changer for four-wheelers whose main motive is to reduce the gear shifting time without losing the broken power and to improve efficiency by eliminating the wear and tear.

5. P.Madhu Raghava, et al says that the fossil fuels such as petroleum, diesel, etc. which meet most of the energy demand of the world are depleted rapidly, so they are giving an alternative way which is an airpowered bicycle.

6. Pawan R. Gurav, et al says that their main motive of the project is to bring automation in gear shifter of two-wheelers using the stepper motor. It is 
controlled by buttons that give instructions to the stepper motor through programming to achieve the control motion.

7. Akash Deep, et al describes that their project is a pneumatic gear shifter especially for two-wheelers to make the gear shifting smoother and to reduce the gear shifting time.

8. K Shashank, et al says that the gear shifting mechanism is playing an important role in the conservation of fuel and energy and have developed a voice-activated gear shifting mechanism, especially for handicapped people.

9. S Vijay Kumar, et al describes their project as it was designed and applied to make the gear shifting process faster and less destructible for the driver and the shifting is done automatically with the help of PLC, Two pneumatic double-acting cylinders, and a relay.

10. Chethan J, et al describes that the project aims to automate the gear transmission in a gear featured bike to ease the driving and to improve efficiency. and the gear shifting is done by an automatic transmission system which shifts the gear concerning the speed of the vehicle.

11. Mr.Uzair Ahmed Shaikh, et al describes their project as about automating the gear shifting mechanism in two-wheelers using an electromagnetic actuator. and it will increase the fuel efficiency and human invention with the help of an electromagnetic actuator placed with the lever which helps to shift the gear according to the speed.

12. Mr.Mayuresh N, et al says that the motorcycle is the only engine-based vehicle that is used on large scale particularly in India.CVT transmission does not have the meshing of gears which enhances a smooth ride but the fuel efficiency is low compared to the gear vehicles so the idea of the project is to automate the gear shifting process with the help of embedded systems and microcontrollers to improve the efficiency and comfort while driving.

13. Daofei Li, et al describes that the braking energy recovery can significantly contribute to fuel economy and emission reduction, particularly for the commercial vehicles by using compressed air storage rather than using expensive batteries.

14. Bensode Lawrence, et al describes that their project is a pneumatic gear shifting mechanism for a shifter kart and the shifter karts include open-wheel, four-wheeled racing categories with usually no suspension, and the performance comparison is done.
15. Chang- woo song, et al describes their project as a solenoid actuator with a ferromagnetic plunger to generate both rectilinear and turning motions of a multi-segmented robot.

16. Jp Yadav, et al says that the world is hardpressed with energy and fuel crises compound with pollution of all kinds so they have developed a new engine called as compressed air engine which does not require any of the fuels like diesel, petrol.

17. James D. Van de ven, et al describes that their project is a vehicle drive train to improve the fuel efficiency of a passenger of car and the developed hydro-mechanical drive train enables independent control of the torque at each wheel and the motive for this project is a hydraulic hybrid vehicle.

18. Yongjing Huang, et al says that the shift schedule of saving energy to keep the torque converter working high efficiency. It carries on the further study of saving energy shift theory and presents the control method of saving energy shift schedule.

19. Romesh Makwana, et al describes that the conventional gearboxes are capable to vary the gear arrangement according to fluctuating load. It fabrication of an automated gearbox and comparison of torque, rpm is carried out with standard elementary equations and the performance can be increased by varying the design parameters of gears and pre-requisite.

20. Siddharth Dahiya, et al describes the paper as about the design methodology and algorithm development on the design of external gear shifting and clutch actuation system for the sequential gearbox. The project is to provide the drivers with an easier and an efficient means of shifting gears.

\section{CONCLUSIONS}

The various research works show that it becomes very difficult to change the gear frequently in situations such as traffic. Automatic transmission is used to modify this and give the rider superior comfort, reduce human effort and improve the efficiency of the vehicle as well. By the proposed system, shifting of the gear system is more flexible, and more system becomes reliable.

\section{REFERENCES}

1. Prof. Mankar N.A and Mr. keshar S.D; "Electro-pneumatic Gear Shifting Mechanism", March 2016.

2. Vijay jadhav and Harshad murhe; "Semiautomatic pneumatic gear shifting", March 2017. 


\section{International Journal of Engineering Applied Sciences and Technology, 2021 \\ Vol. 6, Issue 1, ISSN No. 2455-2143, Pages 314-318 \\ Published Online May 2021 in IJEAST (http://www.ijeast.com)}

3. Amol shitole and pavan kotari; "Solenoid Operated Gear shifting Mechanism for TwoWheeler", July 2018.

4. N.Venkatesh and P. Karthikeyan; "Pneumatic Gear Changer for four-wheelers", June 2017.

5. P. Madhu Raghava and T. Lokesh; "Design and Fabrication of Pneumatic Powered Two-Wheeler", April 2017.

6. Pawan R.Gurav and Rajesh M. Mhatre; "Button Operated Gear Shifter in Two Wheeler using Stepper Motor", March 2017.

7. Akash Deep and Shivam Sudarshan Verma; "Design and Fabrication of Pneumatic based gear shifter for two-wheeler application", November 2018.

8. K. Shashank and Karthik Raja; "Voice operated gear shifting mechanism for Handicapped", January 2019.

9. S.Vijay Kumar and P. Nithesh Reddy; "Fabrication of Pneumatic Gear Changer", June 2016.

10. Chethan J and Darshan Naik; "Design and fabrication of automated manual gear transmission in motorbikes", April 2016.

11. Mr. Uzair Ahmed shaikh; "Automatic Gear Shifting Mechanism in two-wheelers using Electromagnetic Actuator", September 2018.

12. Mr. Mayuresh N Pote; "Automated Gear Transmission in Two-Wheeler using Embedded system”, August 2018.

13. Li Daofei; "A pneumatic hybrid system with an integrated compressor/Expand unit for commercial vehicles", February 2014.

14. Lawrence Bensode; "Design and Implementation of Pneumatic Gear Shifting Mechanism for Shifter Kart”, May 2020.

15. Shan Chang- woo song; "Design of a Solenoid Actuator with a Magnetic Plunger for Miniaturized Segment Robots", April 2015.

16. Jp Yadav; "Study and Fabrication of Compressed Air Engine", January 2011.

17. James D. Van de ven; "Development of a HydroMechanical Hydraulic Hybrid Drive Train with Independent Wheel Torque Control for an Urban Passenger Vehicle", May 2015.
18. Yongjing Huang; "Hybrid intelligent gearshift control of technical vehicles based on AGA-NN", September 2013.

19. Makwana Romesh; "Analysis of Auto-Gear Shifting Mechanism on different Load Conditions", May 2014.

20. Dahiya Siddharth; "Electro-Pneumatic Shifting System and Gear Control Unit for a Sequential Gearbox”, June 2016.

21. S. Suresha, B. K. Sridhara, "Effect of addition of graphite particulates on the wear behavior in aluminum-silicon carbide - graphite composites", 2009.

22. L. M. Tham, M. Gupta, and L. Cheng: "Effect of Limited Matrix[1]Reinforcement Interfacial Reaction On Enhancing the Mechanical Properties of Aluminium - Silicon carbide Composite", 2001.

23. Venkatesh, S., Kumar, R.S., Sivapirakasam, S.P., Sakthivel, M., Venkatesh, D. and Arafath, S. Y., 2020. Multi-objective optimization, experimental and CFD approach for performance analysis in a square cyclone separator. Powder Technology, 371, pp.115-129.

24. Kumar, R.S., Alexis, J. and Thangarasu, V.S., 2017. Optimization of high-speed CNC end milling process of BSL 168 Aluminium composite for aeronautical applications. Transactions of the Canadian Society for Mechanical Engineering, 41(4), pp. 609-625. [14] Kumar, S.R., Alexis, J.S. and Thangarasu, V.S., 2017. Experimental Investigation of Influential Parameters in HighSpeed Machining of AMS 4205. Asian Journal of Research in Social Sciences and Humanities, 7(2), pp. 508-523.

25. Alexis, J. and Thangarasu, V.S., 2016. Prediction of machining parameters for A91060 in end milling. Advances in Natural and Applied Sciences, 10(6 SE), pp. 157-164.

26. Kumar, R. S., Thangarasu, V. S. and Alexis, S. J., 2016. Adaptive control systems in CNC machining processes--a review. Advances in Natural and Applied Sciences, 10(6 SE), pp. 120-130.

27. T. Ramakrishnan, $M$ Sathesh Babu, S Balasubramani, K Manickaraj, R Jeyakumar., 2021. Effect of Fiber Orientation and Mechanical Properties of Natural Fiber Reinforced Polymer Composites-A Review, paideumajournal.14 (3), pp. 17-23. 
28. Jeyakumar $\mathrm{R}$, Balasubramanian $\mathrm{K}$, Ramamoorthi R, Ramakrishnan T., 2021, Development of Compact Electro Gear Pump for Airborne Applications. Paideumajournal, 14 (3), pp.50-57.

29. Ramakrishnan, T. and Sampath, P.S., 2017. Dry sliding wear characteristics of new short agave Angustifolia marginata (AAM) fiber[1]reinforced polymer matrix composite material. Journal of Biobased Materials and Bioenergy, 11(5), pp. 391399.

30. Thirumalaisamy, R. and Subramani, S. P., 2018. Investigation of physico[1]mechanical and moisture absorption characteristics of raw and alkali-treated new agave Angustifolia marginata (AAM) fiber. Materials Science, 24(1), pp. 53-58.

31. Jeyakumar, R., Sampath, P.S., Ramamoorthi, R. and Ramakrishnan, T., 2017. Structural, morphological, and mechanical behavior of glass fiber reinforced epoxy nanoclay composites. The International Journal of Advanced Manufacturing Technology, 93(1), pp. 527-535.

32. Ramakrishnan, T. and Sampath, P.S., 2017. Experimental investigation of mechanical properties of untreated new Agave Angustifolia Marginata fiber-reinforced epoxy polymer matrix composite material. Journal of Advances in Chemistry, 13(4), pp. 6120-6126.

33. Ramakrishnan, T., Sampath, P.S. and Ramamoorthi, R., 2016. Investigation of mechanical properties and morphological study of the alkalitreated agave Angustifolia marginata fiberreinforced epoxy polymer composites. Asian Journal of Research in Social Sciences and Humanities, 6(9), pp. 461-472

34. Sathish, K., Ramakrishnan, T. and Sathishkumar, S., 2016. Optimization of turning parameters to improve the surface finish of $16 \mathrm{Mn}$ Cr 5 material. Advances in Natural and Applied Sciences, 10(6 SE), pp. 151-157.

35. Ramakrishnan, T., Sathish, K., Sampath, P.S. and Anandkumar, S., 2016. Experimental investigation and optimization of surface roughness of AISI 52100 alloy steel material by using the Taguchi method. Advances in Natural and Applied Sciences, 10(6 SE), pp. 130-138.

36. Ramakrishnan, T. and Sampath, P.S., 2016. Thermogravimetric Analysis (TGA) and the Effect of Moisture Absorption on the Mechanical Properties of New Agave Angustifolia Marginata 3 Fiber (AAMF) Reinforced Epoxy Polymer Composite Material. International Journal of
Printing, Packaging \& Allied Sciences, 4(5), pp. 3245-3256.

37. Gokilakrishnan, G. and Varthanan, P.A., 2019. Development of manufacturing distribution plan considering the quality cost. International Journal of Enterprise Network Management, 10(3-4), pp. 280304.

38. Varthanan, P. A. and Gokilakrishnan, G., 2018. Simulation-Based Swarm Intelligence to Generate Manufacturing-distribution Plan for a Bearing Industry under Uncertain Demand and Inventory Scenario. International Journal of Pure and Applied Mathematics, 119(12), pp. 2117-2134.

39. Gokilakrishnan, G.E., Divya, S., Rajesh, R. and Selvakumar, V., 2014. Operating torque in ball valves: a review. Int J Technol Res Eng, 2(4), pp. 311-315.

40. Suresh Kumar, R., John Alexis, S. and Thangarasu, V.S., 2015. Application of GA \& ANN for the optimization of cutting parameters for end milling operation-A comparison. International Journal of Applied Engineering Research, 10(20).

41. Rabindra Behera, S. Kayal, N. R. Mohanata, G. Sutradhar: "Study on Machinability of Aluminium Silicon Carbide Metal Matrix Composites".

42. Venkatesh, S., Sivapirakasam, S. P., Sakthivel, M., Ganeshkumar, S., Prabhu, M. M. and Naveenkumar, M., 2021. Experimental and numerical investigation in the series arrangement square cyclone separator. Powder Technology, 383, pp. 93-103.

43. Venkatesh, S., Sakthivel, M., Saranav, H., Saravanan, N., Rathnakumar, M., and Santhosh, K.K., 2020. Performance investigation of the combined series and parallel arrangement cyclone separator using experimental and CFD approach. Powder Technology, 361, pp. 1070-1080.

44. Venkatesh, S., Sakthivel, M., Avinasilingam, M., Gopalsamy, S., Arulkumar, E. and Devarajan, H.P., 2019. Optimization and experimental investigation in bottom inlet cyclone separator for performance analysis. Korean Journal of Chemical Engineering, 36(6), pp. 929-941.

45. Venkatesh, S., Sakthivel, M., Sudhagar, S. and Daniel, S.A.A., 2018. Modification of the cyclone separator geometry for improving the performance using Taguchi and CFD approach. Particulate Science and Technology.

46. Venkatesh, S. and Sakthivel, M., 2017. Numerical investigation and optimization for 
performance analysis in Venturi inlet cyclone separator. Desalination and Water Treatment, 90, pp. 168-179.

47. Subramaniam, B., Natarajan, B., Kaliyaperumal, B. and Chelladurai, S.J.S., 2019. Wear behavior of aluminum 7075 boron carbide-coconut shell fly ash reinforced hybrid metal matrix composites. Materials Research Express, 6(10), p. 1065d3.

48. Subramaniam, B., Natarajan, B., Kaliyaperumal, B. and Chelladurai, S.J.S., 2018. Investigation on mechanical properties of aluminum 7075- boron carbide-coconut shell fly ash reinforced hybrid metal matrix composites. China Foundry, 15(6), pp. 449-456.

49. N. Balaji, S. Balasubramani, V. Pandiaraj., 2021, Fabrication and Analysis of Al6061/Al2O3/TiC Hybrid Metal Matrix Composite, Paideuma Journal of Research., Vol 14, No 3, pp 24-35.

50. Balasubramani, S., Dhanabalakrishnan, K.P. and Balaji, N., 2015. Optimization of machining parameters in aluminum HMMC using response surface methodology. International journal of applied engineering research, 10(20), pp. 1973619739.

51. Balasubramani S, Manikandan.S Prasath.P, Suresh.D and Shanmuga Sundaram.P., 2018. "Vibration Analysis of Work Holding Devices in Composite Materials" International Journal for Scientific Research \& Development, vol. 6, no. 2, pp. 2520-2523.

52. Balasubramani, S. and Balaji, N., 2016. Investigations of vision inspection method for surface defects in image processing techniques-a review. Advances in Natural and Applied Sciences, 10(6 SE), pp.115-120.

53. Ganeshkumar S, Sureshkumar R, Sureshbabu Y, Balasubramani S, 2020, A Review On Cutting Tool Measurement in Turning Tools by Cloud Computing Systems in Industry 4.0 And IoT, GIS Science Journal, vol. 7, no. 8, pp. 1-7.

54. Ganeshkumar S, Sureshkumar R, Sureshbabu Y, Balasubramani S, 2019, A Numerical Approach to Cutting Tool Stress in CNC Turning of En8 Steel with Silicon Carbide Tool Insert, International Journal of Scientific \& Technology Research, vol. 8, no. 12 , pp. 3227-3231.

55. Ganeshkumar, S., Thirunavukkarasu, V., Sureshkumar, R., Venkatesh, S. and Ramakrishnan, T., 2019. Investigation of wear behavior of silicon carbide tool inserts and titanium nitride coated tool inserts in the machining of en8 steel. International
Journal of Mechanical Engineering and Technology, 10(01), pp. 1862-1873.

56. Venkatesh, S., Sivapirakasam, S.P., Sakthivel, M., Ganeshkumar, S., Prabhu, M. M. and Naveenkumar, M., 2021. Experimental and numerical investigation in the series arrangement square cyclone separator. Powder Technology, 383, pp. 93-103.

57. Kumar, S. G. and Thirunavukkarasu, V., 2016. Investigation of Tool Wear and Optimization of Process Parameters in Turning of EN8 and EN 36 Steels. Asian Journal of Research in Social Sciences and Humanities, 6(11), pp. 237-243.

58. Ganesh Kumar, S., Suresh Kumar, R., Suresh Babu, M.Y. and Balasubramani, M. S., A Review of Performance Investigations in Hydrogen-Oxygen Generator for Internal Combustion Engines.

59. R. Warren, C. H. Andersson, "Silicon carbide fibers and their potential for use in composite materials", 1984. 